\title{
KAJIAN PENAMBAHAN DUMMY ALUMINUM PADA POSISI IRADIASI SENTRAL (CIP) TERHADAP PARAMETER NEUTRONIK REAKTOR RSG- GAS
}

\section{STUDY OF ADDITION ALUMINIUM DUMMY IN CENTRAL IRRADIATION POSITION (CIP) ON RSG-GAS REACTOR NEUTRONIC OPERATION PARAMETERS}

\author{
Susanto $^{1}$, Fitri Susanti ${ }^{2}$ \\ 1,2Pusat Reaktor Serba Guna - BATAN \\ Kawasan PUSPIPTEK Gd.No.30, Setu, Tangerang Selatan, 15310 \\ Email: Susanto3400@batan.go.id
}

Diterima: 29 April 2019, diperbaiki: 8 Mei 2019, disetujui: 14 Mei 2019

\begin{abstract}
ABSTRAK
KAJIAN PENAMBAHAN DUMMY ALUMINIUM PADA POSISI IRADIASI SENTRAL (CIP) TERHADAP PARAMETER NEUTRONIK REAKTOR RSG-GAS. Reaktor RSG-GAS adalah reaktor riset yang dioperasikan untuk keperluan produksi radioisotop, analisis aktivasi neutron, penelitian dan uji material. Reaktor RSG-GAS beroperasi dengan rata-rata energi terbangkitkan sebesar 625 MWd setiap siklus dan manajemen bahan bakar teras menggunakan pola 5/1 untuk pemuatan bahan bakar. Setiap pergantian teras dilakukan perhitungan dan pengukuran parameter reaktor untuk mengetahui pengaruh terhadap keselamatan operasi reaktor. Pada kondisi operasi normal fasilitas iradiasi dalam teras berisi air atau dummy aluminium. Penambahan dummy aluminium pada fasilitas iradiasi perlu diketahui pengaruhnya terhadap parameter neutronik reaktor RSG-GAS. Tujuan penulisan makalah ini yaitu melakukan perhitungan dan pengukuran parameter operasi reaktor dan mengetahui pengaruh penambahan dummy aluminium terhadap reaktivitas dan fluks neutron pada teras 97 reaktor RSG-GAS. Perhitungan parameter operasi dilakukan menggunakan kombinasi program WIMS/D5 untuk generasi tampang lintang sel, Batan-2DIFF untuk menghitung reaktivitas dan faktor puncak daya radial serta Batan-3DIFF untuk menghitung faktor puncak daya aksial dan fluks neutron dalam teras reaktor. Efek reaktivitas akibat penempatan dummy aluminium pada CIP sebesar 0,17 $\% \Delta k / k$. Jika dummy aluminium diletakkan di CIP dan IP akan menaikkan fluks di posisi tersebut karena aluminium mempunyai daya moderasi yang sangat baik. Nilai faktor puncak daya radial dan aksial masing-masing 1,2200 dan 1,2902. Berdasarkan hasil perhitungan dan pengukuran besaran tersebut masih berada dalam batas yang diizinkan untuk keselamatan operasi reaktor dan menunjukan bahwa teras 97 reaktor RSG-GAS memenuhi batas keselamatan operasi reaktor.
\end{abstract}

Kata kunci: Dummy aluminium, reaktivitas, fasilitas iradiasi, operasi reaktor

\section{ABSTRACT}

STUDY OF ADDITION ALUMINIUM DUMMY IN CENTRAL IRRADIATION POSITION (CIP) ON RSG-GAS REACTOR NEUTRONIC OPERATION PARAMETERS. The RSG-GAS reactor is a research reactor operated for radioisotope production, neutron activation analysis, research and material testing. The RSG-GAS reactor operates for $625 \mathrm{MWd}$ each cycle and core fuel management uses a 5/1 pattern in the fuel loading. Every fuels replacement in the reactor core performed calculating and measured reactor parameters to determine the safety factor of reactor operation. Under normal operating conditions the irradiation facility is in a water or aluminium 
dummy. The addition of aluminum dummy to the irradiation facility needs to be known for its effect on the neutronic parameters of the RSG-GAS reactor. In this paper, we evaluated the calculation and measurement of reactor operating parameters and the dummy effect of aluminium on reactivity and neutron flux of 97 RSG-GAS reactors core. The calculation of operating parameters is done using a combination of WIMS/D5 for the cell generation cross section, Batan-2DIFF to calculate reactivity, radial power peacking factor and Batan-3DIFF to calculate the axial power peacking factor and neutron flux in the reactor core. Based on the results of calculations and measurements indicate that the 97 RSG-GAS reactors core meets the reactor operating safety limit. The reactivity effect due to the placement of the aluminium dummy on the CIP $0.17 \% \Delta \mathrm{k} / \mathrm{k}$. If the aluminium dummy is placed in the CIP and the IP will increase the flux in that position because aluminium has a very good moderating power. The value of power factor for peak radial and axial power is 1.2200 and 1.2902, respectively. The value is still within the safety limit of reactor operations.

\section{Keywords: Dummy aluminum, reactivity, irradiation facilities, reactor operation}

\section{PENDAHULUAN}

Reaktor RSG-GAS memiliki daya nominal $30 \quad \mathrm{MW}$ (termal) dan menghasilkan fluks neutron termal dalam orde $10^{14} \mathrm{n} / \mathrm{cm}^{2} \mathrm{~s}$. Pada teras setimbang menggunakan 40 bahan bakar dan 8 batang kendali dan dikelilingi oleh elemen berilium dan blok berilium sebagai reflektor. Komponen-komponen teras reaktor disusun pada kisi-kisi yang terdiri atas $10 \times 10$ posisi. Reaktor menggunakan air ringan sebagai pendingin teras dan juga sebagai moderator. Elemen bakar yang digunakan jenis MTR dan terdiri dari 21 pelat elemen bakar. Setiap pelat elemen bakar terdiri atas rangka $\mathrm{AlMg}_{2}$ dan dua lembaran penutup dari bahan yang sama, yang membungkus pelat meat dispersi $\mathrm{U}_{3} \mathrm{Si}_{2}-\mathrm{Al}$ kerapatan $2.96 \mathrm{~g} / \mathrm{cc}$ denga pengkayaan $19,75 \% 235 \mathrm{U}$. Elemen bakar kendali terdiri dari 15 pelat elemen bakar dan disisipi penyerap jenis-garpu (fork type). Perangkat penyerap terdiri atas dua bilah $\mathrm{Ag}-\mathrm{In}-\mathrm{Cd}$ yang diberi lapisan baja tahan karat[2].

Reaktor RSG-GAS beroperasi dengan rata-rata energi terbangkitkan sebesar $625 \mathrm{MWd}$ dan setiap teras dilakukan pergantian bahan bakar dengan pola 5/1[7]. Dengan pola 5/1 terdapat 5 buah elemen bakar standar dan 1 buah elemen bakar kendali segar dimasukkan di awal siklus ke teras sebagai ganti dari 5 buah elemen bakar standar dan 1 buah elemen kendali yang sudah mencapai nilai fraksi bakar maksimal. Setiap pergantian teras dihitung ulang nilai parameter neutronik reaktor untuk menjamin reaktor beroperasi dengan selamat.

Pada operasi normal fasilitas iradiasi reaktor RSG-GAS biasanya berisi air. Penempatan dummy aluminium pada fasilitas iradiasi dapat menaikkan reaktivitas dan fluks neutron karena mempunyai daya moderasi yang sangat baik. Oleh karena itu perlu dilakukan perhitungan parameter neutronik untuk mengetahui pengaruh dummy terhadap operasi reaktor. Pengaruh dummy aluminium variasi masa pada fasilitas Iradiasi Posisi (IP) terhadap reaktivitas dan faktor puncak daya radial telah dilakukan dengan menggunakan Batan2DIFF[1]. Akan tetapi pada makalah sebelumnya [1] pengaruh penambahan dummy aluminium pada fasilitas Sentral Iradiasi Posisi (CIP), faktor puncak daya aksial dan fluks neutron belum dapat diperlihatkan. Fasilitas iradiasi CIP 
menjadi penting diperhitungkan karena merupakan posisi sentral untuk iradiasi target dengan kebutuhan fluks neutron tinggi. Penambahan dummy aluminium diharapkan dapat meningkatkan populasi fluks neutron termal karena memiliki kemampuan moderasi yang baik. Oleh karena itu, pada makalah ini akan dibahas parameter operasi reaktor teras 97 dan kajian penambahan dummy aluminium terhadap reaktivitas, faktor puncak daya dan fluks neutron termal pada Posisi Iradiasi Sentral (CIP).

Pengukuran parameter operasi reaktor dilakukan setelah reaktor kritis pada siklus awal teras untuk kemudian dilakukan eksperimen pemuatan reaktivitas lebih. Hasil pengukuran parameter operasi reaktor pada siklus awal teras 97 (Beginning of Cycle/ BOC) dibandingkan dengan hasil perhitungan. Perhitungan parameter operasi reaktor dan pengaruh penambahan dummy aluminum terhadap panjang operasi reaktor dilakukan dengan Batan-2DIFF [8], [9] dan pengaruhnya terhadap faktor puncak daya aksial serta fluks neutron termal dilakukan dengan Batan3DIFF[10]. Pengaruh penambahan dummy aluminium di CIP dan posisi lainnya diharapkan dapat menaikkan fluks di posisi tersebut karena aluminium mempunyai daya moderasi yang sangat baik. Program Batan-2DIFF dan Batan3DIFF telah divalidasi dengan berbagai data pengukuran reaktor RSG-GAS. Kedua program secara rutin digunakan untuk perhitungan manajemen bahan bakar dan analisis keselamatan operasi reaktor RSG-GAS.

\section{TEORI}

\section{Fasilitas Iradiasi}

Reaktor RSG-GAS mempunyai 4 buah Posisi Iradiasi Sentral (CIP) dan 2 buah Posisi Iradiasi (IP) pada teras.
Selain itu didalam teras ada 5 fasilitas sistem rabbit, tujuh elemen reflektor berilium memiliki lubang berdiameter 50 $\mathrm{mm}$ dan dapat digunakan sebagai fasilitas iradiasi reflektor atau diisi dengan berilium bila tidak digunakan[3]. Fasilitas iradiasi dalam teras reaktor digunakan untuk produksi radioisotop, batu topaz, analisis aktivasi neutron, permintaan dari industri, lembaga litbang dan universitas[4]-[6]. Selain fasilitas iradiasi dalam teras, reaktor RSG-GAS mempunyai 6 tabung berkas neutron yang digunakan untuk penelitian dan fasilitas silicon doping serta fasilitas power ramp test facility (PRTF).

\section{Dummy Aluminium}

Dummy aluminium digunakan untuk satu siklus teras penuh selama pengoperasian reaktor RSG-GAS. Dummy aluminium memiliki kemampuan sebagai moderator neutron yang baik. Apabila tidak dimoderasi dengan dummy aluminium banyak fluks neutron dalam teras yang terbawa oleh aliran pendingin reaktor atau over moderated. Oleh karena itu, dummy aluminium digunakan sebagai penyumbat aliran pendingin pada teras reaktor. Dengan demikian populasi neutron termal dapat terjaga dengan baik dan memperpanjang siklus operasi reaktor karena gangguan neutron yang hilang akibat terbawa aliran pendingin primer menjadi sangat sedikit [1].

Bentuk dummy aluminium berupa pengarah bulat panjang dan berongga berisi aluminium sebagai pemberat sedang. Pada operasi normal posisi IP dan CIP yang tidak digunakan untuk iradiasi target dipasang dummy aluminium sebagai alat bantu moderator neutron sehingga terjadi keseimbangan pembelahan inti dan operasi reaktor yang baik.

\section{Program Perhitungan WIMS/D5, Batan-2DIFF dan Batan-3DIFF}


Paket program WIMS merupakan paket program yang digunakan dalam perhitungan sel dan menggenerasi konstanta kelompok difusi. Paket program WIMS/D5 merupakan penyempurnaan dari versi sebelumnya, yaitu WIMS/D4. Program WIMS/D5 hanya bisa melakukan perhitungan transport neutron satu dimensi, sehingga dalam penggunaannya perlu dilakukan pemodelan sel teras. Pemodelan Sel teras dilakukan untuk membuat konstanta kelompok makroskopik material teras. Nilai konstanta kelompok yang dihasilkan merupakan nilai konstanta kelompok rerata sel yang diperoleh dengan melakukan homogenisasi material sel[13]. Program perhitungan computer adalah suatu program komputer yang dipergunakan untuk menyelesaikan persamaan difusi neutron dengan banyak kelompok energi dalam geometri 2D dan 3D. Akurasi perhitungan parameter teras reaktor RSG-GAS dengan Batan-2DIFF dan Batan-3DIFF ditentukan oleh tampang lintang material penyusun teras, pemodelan teras yang detail, dan keakuratan perhitungan fraksi bakar tiap elemen bakar dalam teras[13].

\section{METODOLOGI}

Metodologi penelitian ini dilakukan dengan tahapan seperti gambar diagram alir berikut :

(code) Batan-2DIFF dan Batan-3DIFF

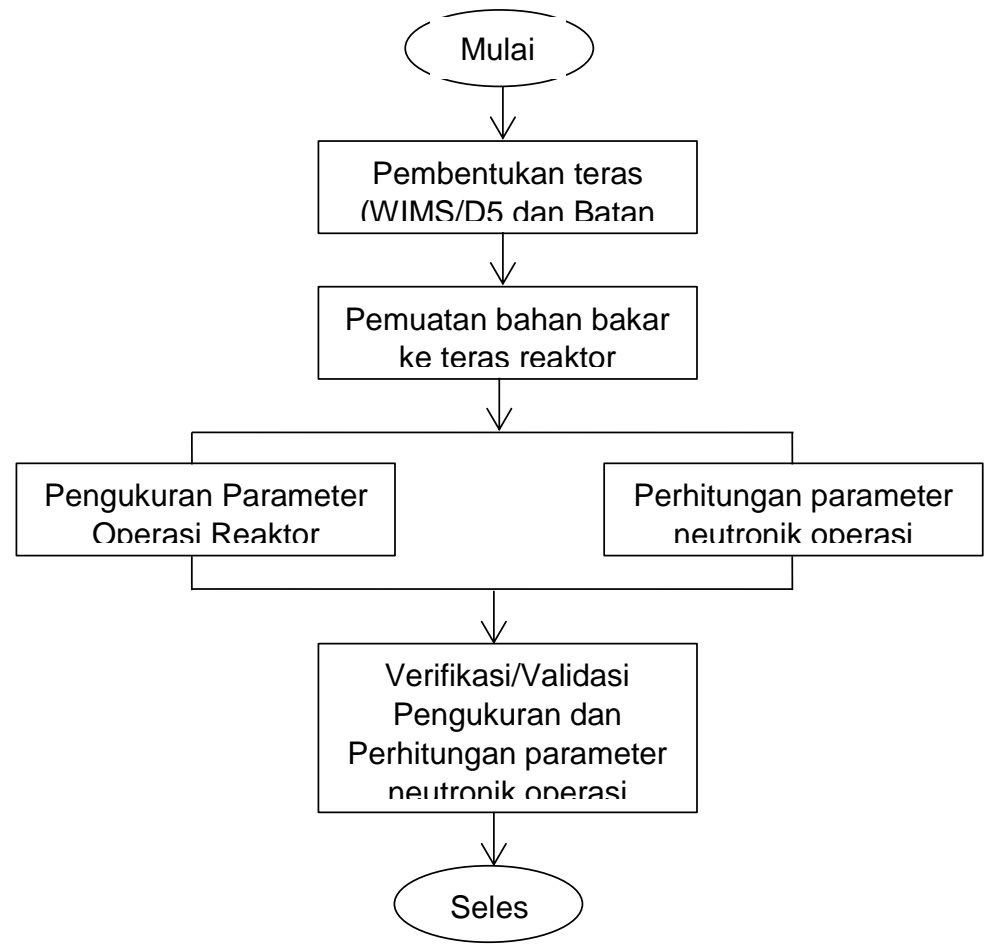

Gambar 1. Diagram alir perhitungan penambahan dummy aluminium pada fasilitas iradiasi

\section{Pembentukan Teras}


Pembentukan teras reaktor RSGGAS menggunakan paket program WIMS/D5 dan BATAN-FUEL. Batasan desain teras yang digunakan untuk menentukan parameter neutronik agar operasi reaktor tetap aman adalah[8]:

a. Reaktivitas lebih maksimum teras $10 \% \Delta \mathrm{k} / \mathrm{k}$

b. Reaktivitas lebih pada saat BOC, dingin dan tanpa $\mathrm{Xe} \leq 10,0 \% \Delta \mathrm{k} / \mathrm{k}$

c. Margin padam yang tersedia pada saat BOC, dingin dan tanpa Xe harus lebih besar dari batas minimum sebesar $-0,5 \% \Delta \mathrm{k} / \mathrm{k}$.

d. Reaktivitas pada saat EOC, panas dan Xe setimbang sekitar $1,7 \% \Delta \mathrm{k} / \mathrm{k}$.

e. Faktor puncak daya (ppf) radial maksimum $\leq 1,4$

f. Reaktivitas target tunggal $<0,5 \%$ $\Delta \mathrm{k} / \mathrm{k}$

g. Reaktivitas total untuk target $<2 \%$ $\Delta \mathrm{k} / \mathrm{k}$

\section{Pemuatan Bahan Bakar ke Teras Reaktor}

Pola manajemen bahan bakar di dalam teras RSG-GAS menggunakan pola $5 / 1$. Dengan pola $5 / 1$ terdapat 5 buah bahan bakar standar dan 1 buah elemen bakar kendali segar dimasukkan di awal siklus ke teras sebagai ganti dari 5 buah bahan bakar standar dan 1 buah elemen kendali yang sudah mencapai nilai fraksi bakar buang rerata sebesar $56 \%$.

Setelah dilakukan perhitungan dengan program Batan-FUEL maka dilakukan pemuatan bahan bakar sesuai dengan langkah pemasukan yang telah ditentukan. Untuk pemuatan bahan bakar, syarat awal yang harus dipenuhi adalah reaktor dalam kondisi sub-kritis, yang mana seluruh batang kendali berada pada posisi teratas.

\section{Pengukuran Parameter Operasi Reaktor}

Pengukuran parameter operasi reaktor dilakukan pada siklus awal teras (BOC). Pengukuran dilakukan setelah tercapai kondisi kritis reaktor yaitu dengan cara menambah bahan bakar satu persatu ke dalam teras reaktor. Setelah reaktor kritis maka dilakukan eksperimen pemuatan reaktivitas lebih. Setiap pemuatan satu elemen bakar dilakukan perhitungan reaktivitas dengan metode kalibrasi batang kendali kompensasi bank. Langkah ini dilakukan sampai terbentuk teras penuh seperti ditunjukkan pada Gambar 2. Sedangkan uji stuck rod dilakukan dimana reaktor sub-kritis pada saat satu batang kendali dengan reaktivitas terbesar berada diatas.

\section{Perhitungan Parameter Neutronik Operasi Reaktor}

Perhitungan parameter operasi reaktor RSG-GAS meliputi perhitungan tampang lintang makroskopis bahan bakar, batang kendali, material pembentuk teras reaktor dan dummy aluminium sebagai data input. Perhitungan tampang lintang bahan bakar dan bahan non fisil dilakukan dengan program WIMS/D5 [10]. Pengaruh penambahan dummy aluminium terhadap reaktivitas dan faktor puncak daya radial dilakukan dengan program Batan-2DIFF, sedangkan faktor puncak daya aksial dan fluks neutron termal pada fasilitas iradiasi dilakukan dengan program Batan-3DIFF.

Teras setimbang reaktor RSGGAS ditunjukkan dalam Gambar 2, dimana fasilitas iradiasi CIP (D-6, D-7, E6, E-7) dan IP (B-6, D-9, E-4, G-7) akan diisi dummy aluminium. Perhitungan awal yang dilakukan adalah tanpa adanya dummy aluminium dalam teras reaktor. Perhitungan ini untuk mengetahui reaktivitas teras sebelum dummy masuk ke dalam teras. Selanjutnya dilakukan pemodelan dummy aluminium secara detail untuk mengetahui pengaruh 
reaktivitas jika ditempatkan pada fasilitas iradiasi. Hal yang sama dilakukan untuk perhitungan koefisien efektif, perubahan reaktivitas, faktor puncak daya (PPF) dan fluks neutron termal.

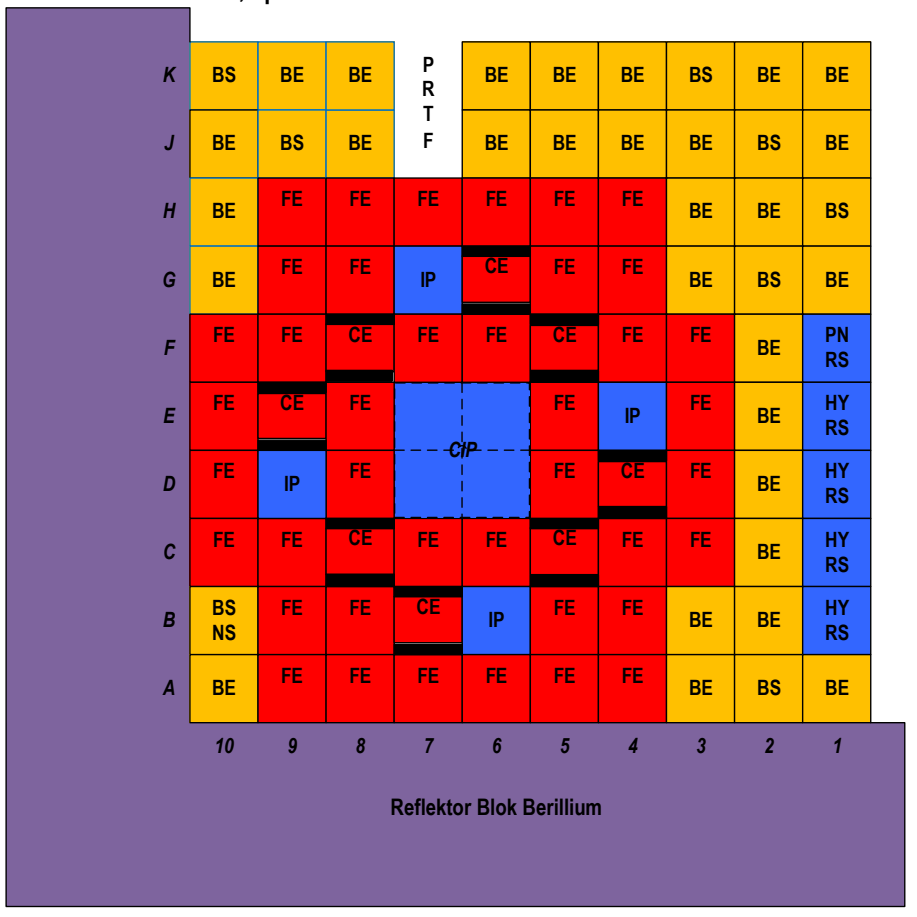

Catatan : FE = Elemen Bakar, $\mathrm{CE}=$ Kontrol Elemen, $\mathrm{BE}=$ Elemen Reflektor Be, $\mathrm{BS}=$ Elemen Reflektor $\mathrm{Be}$ dengan Plug, IP = Posisi Iradiasi, CIP = Posisi Iradiasi Sentral, PNRS = Sistem Rabbit Pneumatik, HYRS = Sistem Rabbit Hidraulik

Gambar 2. Konfigurasi teras setimbang reaktor RSG-GAS [2]

\section{HASIL DAN PEMBAHASAN}

Hasil pengukuran

dan perhitungan neraca reaktivitas teras 97 reaktor RSG-GAS dengan menggunakan program BATAN-2DIFF ditunjukkan pada Tabel 1. Pada Tabel 1 dapat dilihat bahwa perbedaan antara eksperimen dan perhitungan untuk parameter neraca reaktivitas diantara $-32,85 \%$ sampai dengan 20,83\%. Perbedaan terbesar terjadi pada reaktivitas lebih teras yaitu -
$32,86 \%$. Perbedaan terbesar ini diakibatkan karena terjadi efek shadowing sewaktu dilakukan pengukuran dengan metode kalibrasi batang kendali berpasangan. Penelitian sebelumnya menunjukan bahwa secara teoritis efek shadowing batang kendali reaktor RSGGAS dapat mencapai 32\% [12]. Akibat efek tersebut, maka nilai reaktivitas lainnya juga memiliki perbedaan yang besar.

Tabel 1. Neraca rektivitas pada kondisi BOC teras 97 reaktor RSG-GAS 


\begin{tabular}{lccc}
\hline \multirow{2}{*}{ Parameter } & \multicolumn{2}{c}{ Reaktivitas $(\% \Delta \mathrm{k} / \mathrm{k})$} & \multirow{2}{*}{ Perbedaan (\%) } \\
\cline { 2 - 3 } & Pengukuran & Perhitungan & \\
\hline $\begin{array}{l}\text { Reaktivitas total } \\
\text { batang kendali }\end{array}$ & 12,9112 & 14,0350 & $-8,70$ \\
\hline Reaktivitas padam & 5,8102 & 4,5999 & 20,83 \\
\hline Reaktivitas lebih & 7,1011 & 9,4351 & $-32,86$ \\
\hline Reaktivitas stuck rod & 1,8417 & 2,1339 & $-15,86$ \\
\hline
\end{tabular}

Nilai reaktivitas sangat penting untuk keselamatan operasi reaktor. Reaktivitas total batang kendali digunakan untuk memadamkan teras reaktor setiap saat dengan marjin keselamatan yang mencukupi dan untuk pengendalian selama reaktor beroperasi. Apabila batang kendali macet (stuck), sistem pemadaman dirancang menyediakan subkritikalitas yang cukup untuk memadamkan reaktor. Selanjutnya, perubahan nilai reaktivitas akibat dummy aluminium pada fasilitas iradiasi dihitung dengan program BATAN-2DIFF dapat dilihat pada Tabel 2 berikut

Tabel 2. Pengaruh penambahan dummy aluminium pada fasilitas iradiasi terhadap

\begin{tabular}{cccc}
\multicolumn{4}{c}{ reaktivitas } \\
\hline $\begin{array}{c}\text { Fasilitas iradiasi diisi } \\
\text { dummy aluminum }\end{array}$ & keff & $\begin{array}{c}\text { Reaktivitas } \\
(\% \Delta \mathrm{k} / \mathrm{k})\end{array}$ & $\begin{array}{c}\text { Perubahan } \\
\text { reaktivitas }(\% \Delta \mathrm{k} / \mathrm{k})\end{array}$ \\
\hline Tanpa dummy (air) & 1,0897550830 & 8,2362 & - \\
\hline IP (B-6, E-4, G-7, D-9) & 1.0936176777 & 8,5607 & 0,32 \\
\hline CIP (D-6, E-6, D-7, E- & 1,0917814970 & 8,4066 & 0,17 \\
7) & & & 0,49 \\
\hline $\begin{array}{l}\text { CIP dan IP (D-6, E-6, } \\
\text { D-7, E-7, B-6, E-4, G- } \\
\text { 7, D-9) }\end{array}$ & 1,0955767663 & 8,7239 & \\
\hline
\end{tabular}

Penambahan dummy aluminium pada CIP meningkatkan reaktivitas sebesar $0,17 \% \quad \Delta \mathrm{k} / \mathrm{k}$. Penambahan dummy aluminium pada CIP memberikan efek reaktivitas yang lebih kecil dibandingkan di fasilitas iradiasi IP.

Nilai faktor puncak daya (FPD) dengan penambahan dummy aluminium pada fasilitas iradiasi ditunjukkan pada Tabel 3. Nilai FPD radial dihitung dengan program BATAN-2DIFF, sedangkan nilai FPD aksial dihitung dengan program BATAN-3DIFF.

Tabel 3. Nilai FPD penambahan dummy aluminium pada fasilitas iradiasi

\begin{tabular}{ccc}
\hline Dummy & FPD radial & FPD aksial \\
\hline- & 1,2242 & 1,2879 \\
\hline CIP & 1,2186 & 1,2902 \\
\hline IP & 1,2200 & 1,2902 \\
\hline
\end{tabular}

Faktor puncak daya maksimum yang diizinkan di dalam elemen bakar berdasarkan faktor kanal panas nuklir pada arah radial sebesar 1,48 dan desain faktor kanal panas pada arah aksial sebesar 1,77 [2]. Dengan dimasukannya dummy aluminium ke dalam fasilitas iradiasi CIP nilai PPF tidak melewati batas maksimum yang diizinkan. Dengan 
demikian, batasan keselamatan dalam pengoperasian reaktor tetap terpenuhi walaupun dengan adanya penambahan dummy aluminium pada fasilitas iradiasi. Nilai fluks neutron termal dengan masuknya dummy aluminium pada fasilitas iradiasi CIP dihitung dengan program BATAN-3DIFF ditunjukkan pada Tabel 4.

Tabel 4. Nilai fluks neutron rata-rata pada fasilitas iradiasi

\begin{tabular}{cllllllll}
\hline $\begin{array}{c}\text { Dummy } \\
\begin{array}{l}\text { aluminu } \\
\mathrm{m}\end{array}\end{array}$ & \multicolumn{7}{c}{ Fluks neutron termal rata-rata $\left(\times 10^{14} \mathrm{n} / \mathrm{cm}^{2} \mathrm{~s}\right)$} & \\
\cline { 2 - 8 } & $\mathrm{D}-6$ & $\mathrm{D}-7$ & $\mathrm{E}-6$ & $\mathrm{E}-7$ & $\mathrm{G}-7$ & $\mathrm{D}-9$ & $\mathrm{~B}-6$ & $\mathrm{E}-4$ \\
\hline- & 2,540 & 2,550 & 2,553 & 2,553 & 2,096 & 2,213 & 2,111 & 2,172 \\
& 9 & 9 & 2 & 4 & 5 & 6 & 5 & 1 \\
\hline CIP & 2,555 & 2,561 & 2,564 & 2,568 & 2,092 & 2,207 & 2,106 & 2,165 \\
& 2 & 3 & 4 & 4 & 6 & 4 & 9 & 3 \\
\hline IP & 2,531 & 2,540 & 2,543 & 2,544 & 2,197 & 2,314 & 2,210 & 2,273 \\
& 3 & 7 & 9 & 4 & 0 & 0 & 1 & 5 \\
\hline
\end{tabular}

Nilai fluks neutron termal sangat penting untuk reaktor riset karena digunakan untuk iradiasi target dalam fasilitas iradiasi. Nilai fluks neutron termal dengan masuknya dummy aluminium ke fasilitas iradiasi CIP dapat dilihat sesuai Tabel 4. Jika dummy aluminium diletakkan di CIP dan IP akan memberi kenaikan fluks di posisi tersebut karena aluminium mempunyai daya moderasi yang sangat baik. Hal ini menjadi salah satu cara untuk menaikan fluks neutron yaitu dengan menempatkan dummy aluminium pada fasilitas iradiasi. Dengan demikian populasi fluks neutron dapat terjaga dengan baik dan memperpanjang siklus operasi reaktor karena gangguan neutron yang hilang akibat terbawa aliran

\section{REFERENSI}

[1] Sutrisno, Purwadi," Analisis Neutronik Dummy Aluminium di Teras Reaktor RSG-GAS," Seminar Nasional Sains dan Teknologi Nuklir 2017, Bandung, 14 November 2017.

[2] BATAN, "Multipurpose Reactor G.A. Siwabessy Safety Analysis Report. pendingin primer menjadi sangat sedikit akibat termoderasi oleh dummy aluminium.

\section{KESIMPULAN}

Penambahan dummy aluminium pada fasilitas iradiasi CIP dapat menaikan reaktivitas dan fluks neutron termal walaupun tidak sebesar pada posisi IP. Sedangkan nilai FPD masih dalam batas yang diizinkan. Penambahan dummy aluminium ini juga tidak mengganggu keselamatan operasi reaktor, akan tetapi dapat membantu memperpanjang siklus operasi reaktor RSG-GAS.

Rev. 8. Indonesia, 1999," 1999.

[3] Y. E. Yulinato and M. Imron, "Manajemen Pengoperasian Reaktor RSG-GAS," Pros. Semin. Nas. Teknol. dan Apl. Reakt. Nukl. PRSG Tahun 2013, 2013.

[4] Sutrisno, "Analisis Optimasi Target 235 U Pengkayaan Rendah (LEU) Untuk Mendukung Produksi 99 Mo 
Dan Target Batu Topaz di Reaktor RSG-GAS," Ganendra, J. Iptek Nukl., vol. 21 No.1, pp. 25-35, 2018.

[5] S. Pinem, T. M. Sembiring, and P. H. Liem, "Neutronic and ThermalHydraulic Safety Analysis for the Optimization of the Uranium Foil Target in the RSG-GAS Reactor," Atom Indones., vol. 42, no. 3, pp. 123-128, 2016.

[6] S. Pinem, S. Jati, Tukiran, and T. Sembiring, "Optimization of Radioisotope Production at RSGGAS Reactor Using Deterministic Method," Teknologi Indonesia, vol. 35 , no. January 2012, pp. 37-45, 2016.

[7] T. M. Sembiring, Tukiran, and S. Pinem, "Neutronic Design of Mixed Oxide-Silicide Cores for the Core Conversion of RSG-GAS Reactor," Atom Indones., vol. 27, no. 2, pp. 851001, 2001.

[8] P. H. Liem, "Development and Verification of Batan's Standard, Two-Dimensional Multigroup Neutron Diffusion Code," Atom Indones., vol. 20, no. 1, pp. 1-19,
1994.

[9] S. Pinem, P. H. Liem, T. M. Sembiring, and T. Surbakti, "Fuel element burnup measurements for the equilibrium LEU silicide RSG GAS (MPR-30) core under a new fuel management strategy," Ann. Nucl. Energy, vol. 98, 2016.

[10] P. H. Liem, "Validation of BATAN'S Standard 3-D Diffusion Code, BATAN-3DIFF, on the First Core of RSG GAS," Atom Indones., vol. 25, no. 1, pp. 47-53, 1999.

[11] WIMSD5, "Deterministic Multigroup Reactor Lattice Calculations, NEA1507/04." 2004.

[12] L. P. Hong, T. Taryo, T. M. Sembiring, S. Hiroshi, and N. Yoshitaka, "Study on the control rod interaction effect in RSG gas multipurpose reactor (MPR-30)," Ann. Nucl. Energy, vol. 29, no. 6, pp. 701-716, 2002.

[13] T. M. Sembiring, "Penggunaan Paket Program WIMSD/5B.12 dan BATAN2DIFF untuk RSG-GAS," PRSG, April, 2011. 